Published in final edited form as:

J Acquir Immune Defic Syndr. 2006 October 1; 43(2): 226-233. doi:10.1097/01.qai.

$0000230527.17459 .5 \mathrm{c}$.

\title{
Factors Associated With Self-Efficacy for Condom Use and Sexual Negotiation Among South African Youth
}

\author{
Jennifer N. Sayles, MD*, Audrey Pettifor, PhD ${ }^{\star}$, Mitchell D. Wong, MD, PhD ${ }^{*}$, Catherine \\ MacPhail, PhD $\ddagger$, Sung-Jae Lee, PhD§, Ellen Hendriksen, BA ${ }^{l}$, Helen V. Rees, MD $^{\dagger}$, and \\ Thomas Coates, PhD \\ "Division of General Internal Medicine and Health Services Research, Department of Medicine, \\ University of California, Los Angeles, Los Angeles, CA \\ tDepartment of Epidemiology, University of North Carolina at Chapel Hill, Chapel Hill, NC \\ ¥Reproductive Health and HIV Research Unit, University of Witwatersrand, Johannesburg, South \\ Africa \\ $\S$ Neuropsychiatric Institute, Center for Community Health, University of California, Los Angeles, \\ Los Angeles, CA \\ "Department of Psychology, University of California, Los Angeles, Los Angeles, CA \\ IDivision of Infectious Disease, Department of Medicine, University of California, Los Angeles, \\ Los Angeles, CA
}

\section{Abstract}

Objectives-To use logistic regression modeling to identify factors associated with high selfefficacy for sexual negotiation and condom use in a sample of South African youth.

Methods-The Reproductive Health and HIV Research Unit (RHRU) National Youth Survey examined a nationally representative sample of 7409 sexually active South African youth aged 15 to 24 years. We used logistic regression modeling in this sample to identify factors associated with the main outcome of high self-efficacy.

Results-Among female respondents $(\mathrm{n}=3890)$, factors associated with high self-efficacy in the adjusted model were knowing how to avoid HIV (odds ratio $[\mathrm{OR}]=2.30,95 \%$ confidence interval [CI]: 1.05 to 5.00), having spoken with someone other than a parent or guardian about HIV/AIDS $(\mathrm{OR}=1.46,95 \% \mathrm{CI}: 1.01$ to 2.10$)$, and having life goals $(\mathrm{OR}=1.28,95 \% \mathrm{CI}: 1.10$ to 1.48$)$. Not using condoms during their first sexual encounter ( $\mathrm{OR}=0.61,95 \%$ CI: 0.50 to 0.76$)$, a history of unwanted sex (OR $=0.66,95 \%$ CI: 0.51 to 0.86$)$, and believing that condom use implies distrust in one's partner ( $\mathrm{OR}=0.57,95 \% \mathrm{CI}$ : 0.51 to 0.86$)$ were factors associated with low self-efficacy among female respondents. Male respondents $(\mathrm{n}=3519)$ with high self-efficacy were more likely to take HIV seriously ( $\mathrm{OR}=4.03,95 \% \mathrm{CI}$ : 1.55 to 10.52$)$, to believe they are not at risk for HIV $(\mathrm{OR}=1.38,95 \% \mathrm{CI}: 1.12$ to 1.70$)$, to report that getting condoms is easy $(\mathrm{OR}=1.85,95 \% \mathrm{CI}$ : 1.23 to 2.77 ), and to have life goals ( $\mathrm{OR}=1.30,95 \% \mathrm{CI}$ : 1.10 to 1.54 ). Not using condoms during their first sexual experience (OR $=0.51,95 \% \mathrm{CI}: 0.39$ to 0.67 ), a history of having unwanted sex $(\mathrm{OR}=0.47,95 \% \mathrm{CI}: 0.34$ to 0.64$)$, believing condom use is a sign of not trusting one's partner $(\mathrm{OR}=0.63,95 \% \mathrm{CI}: 0.46$ to 0.87$)$, and refusing to be friends with HIV-infected persons $(\mathrm{OR}=$

Copyright ( 2006 by Lippincott Williams \& Wilkins

Reprints: Jennifer N. Sayles, MD, UCLA Division of General Internal Medicine and Health Services Research, 911 Broxton Plaza, PO Box 951736, Los Angeles, CA 90095-1736 (jsayles@ mednet.ucla.edu). . 
$0.52,95 \%$ CI: 0.32 to 0.85 ) were factors associated with low self-efficacy among male respondents in the fully adjusted model.

Conclusions-We used the social cognitive model (SCM) to identify factors associated with self-efficacy for condom use and sexual negotiation. Many of these factors are modifiable and suggest potential ways to improve self-efficacy and reduce HIV sexual risk behavior in South African youth.

\section{Keywords}

adolescents; condom use; gender; HIV; self-efficacy; South Africa

HIV prevalence in South African youth is alarmingly high and disproportionately affects girls and women, with one quarter of women aged 20 to 24 years infected with HIV compared with 1 in every 14 men of the same age. $1^{-3}$ Consistent condom use and negotiation of safer sex are the most effective means of HIV risk reduction for sexually active youth, yet studies have shown that in South Africa, rates of condom use are far from ideal and are lower for women (48\%) than for men (53\%-57\%). ${ }^{1-4}$ In South Africa, condoms are widely available at no cost, $1,3,5,6$ and most South African youth report they know that condoms prevent HIV, sexually transmitted infections (STIs), and unwanted pregnancy. ${ }^{7}$ Accessibility and knowledge about condoms have not translated into condom use for many youth, however.

Self-efficacy is having confidence in one's ability to perform a particular behavior, and high self-efficacy for condom use is strongly associated with consistent condom use. ${ }^{4,8-12}$ Rooted in social cognitive theory, the concept of self-efficacy is an important component of healthrelated behavioral change. ${ }^{13,14}$ According to this model, self-efficacy may be shaped by social norms, knowledge, outcome expectations, and communication with family and community members. ${ }^{13}$ Previous studies of HIV risk behaviors and sexual health have consistently shown that high self-efficacy for condom use is strongly associated with the behaviors of condom use with recent partners and consistent condom use. ${ }^{10-12}$ Little is known about the factors that influence self-efficacy and how they may differ by gender, however. In addition, few data on self-efficacy for condom use and sexual negotiation among sub-Saharan African youth exist; yet, this population is at particularly high risk for HIV infection.

We used data from the 2003 Reproductive Health and HIV Research Unit (RHRU) National Youth Survey, a nationally representative household survey of HIV prevalence and sexual behavior among South African youth aged 15 to 24 years, to identify factors associated with self-efficacy for sexually experienced female and male youth. We evaluate the usefulness of self-efficacy and the social cognitive model (SCM) for understanding condom use in this population and explore factors associated with self-efficacy that may inform the development of interventions to reduce HIV risk behavior.

\section{METHODS}

\section{Study Population}

The RHRU National Youth Survey used a 3-stage, disproportionate, stratified sampling design. The 2001 National Census was used as the sampling frame, with census enumeration areas (EAs) used as the primary sampling unit (PSU). Households within sampled EAs were enumerated, and 1 eligible young person per household was randomly selected for the study. A total of 15,414 enumerated and eligible households (youth between the age of 15 and 24 years old) and 2063 households that were not enumerated but presumed to have an eligible 
youth were sampled. A total of 11,904 interviews were completed, resulting in an overall response rate of $68.2 \%$. The sample for this analysis was restricted to youth who reported having had vaginal or anal sex, totaling 7686 respondents. After excluding 277 youth because of missing data ( $3.6 \%$ of the 7686 sexually active youth), the final analytic sample included 7409 youth.

Experienced interviewers aged 18 to 35 years underwent a week-long training session and were matched to interviewees on the basis of gender, language, and race. Interviews were conducted in private. All questionnaires used in the face-to-face interviews were translated from English into 8 official South African languages and then back-translated to ensure accuracy. The survey collected information about demographics; general attitudes about health, relationships, and sexual behaviors; attitudes about relationships, sexual behaviors, and HIV/AIDS; health-seeking behavior; alcohol and drug use; STIs; and pregnancy. Anonymous oral fluid specimens were collected for HIV testing (Orasure HIV-1 Specimen Collection Device; Orasure Technologies, Inc.). Informed consent was obtained for all participants, and parental consent was also obtained for youth aged 15 to 17 years old. The study was approved by the Committee for the Protection of Human Subjects, University of the Witwatersrand, Johannesburg, South Africa.

\section{Measures of Self-Efficacy for Condom Use and Sexual Negotiation}

A self-efficacy index for condom use and sexual negotiation was created using the 5 questions listed in Table 1 . This scale was constructed in part from a previously validated 14-item scale of condom self-efficacy. ${ }^{15}$ Questions regarding condom use all loaded on the communication self-efficacy factor from the previously validated scale. Response scores ranged from 1 to 4 for each question in the self-efficacy index, resulting in a 20-point scale (Cronbach $\alpha$ of 0.64 for women and 0.60 for men). Persons who had a total self-efficacy index score of 16 to 20 (ie, on average, answered "yes" to each of the 5 self-efficacy questions listed in Table 1) were categorized as having "high self-efficacy," and those with a score less than 16 were categorized as having "low self-efficacy." We chose this cutoff because high self-efficacy would be reflected in affirmative (yes) answers to each question. Because of the positively skewed responses, a continuous outcome with linear regression was not an appropriate model; thus, the cutoff point of 15 was chosen based on the distribution of the data. The results were similar in a sensitivity analysis using an alternative cutoff of 10 (dichotomized scores of $0-10$ vs. 11-20, indicating that a respondent, on average, answered "probably yes" to each question).

\section{Measures of Sociodemographic Characteristics}

Sociodemographic characteristics included gender (male or female), age (range: 15-24 years), race (categorized as black or not black, because $86 \%$ of the sample reported black race), history of completing high school, being unemployed and not in school, urban versus rural residence, and having no electricity in the home. Based on our previous experience, youth do not have reliable information about their household income; thus, we used lack of electricity in the home as a marker of poverty.

\section{Measures of Condom Use (Behavior of Interest)}

Condom use consistency with the last sexual partner and condom use at the last sexual encounter were assessed for male $(n=3519)$ and female $(n=3890)$ respondents who reported having sex in the past 12 months. Respondents were asked: "How often did you use condoms with your last sexual partner?" Response options were "always," "more than half of the time," "half of the time," "less than half of the time," and "never." Based on the distribution of responses, we dichotomized those who responded "always" versus all others. Condom use at the last sexual encounter was determined by asking respondents: "The last 
time you had sex with your most recent sexual partner, did you use a condom?" Response options were "Yes" or "No."

\section{Measures of Candidate Factors Associated With Self-Efficacy}

Candidate variables were identified using the Bandura SCM (conceptual model and variables in Fig. 1), where self-efficacy and its effects on condom use are influenced by the individual's knowledge of HIV (whether the respondent takes HIV seriously, has ever been tested for HIV, or has knowledge that there is something one can do to avoid HIV), prior sexual experiences (early sexual debut at age $<15$ years old; use of condoms the first time the respondent had sex; or history of unwanted, forced, or threatened sex), outcome expectations (risk of HIV or condom use as a sign of distrust), sociodemographic characteristics of the individual, sociostructural facilitators (ability to talk with parents or others about HIV, easy access to condoms, or relationship control), sociostructural impediments (partner makes decisions about condom use, would not be friends with someone with HIV [representing HIV stigma], peer pressure to have sex, or having ever used alcohol or drugs), and life goals.

\section{Measure of Relationship Control}

The relationship control variable was based on the previously published relationship control index score 16 from these survey data that was adapted from the Sexual Relationship Power Scale.17,18 The questions in the relationship control index included agree or disagree responses to the questions: "Your partner has more control than you do in important decisions that affect your relationship," "When you and your partner have an argument, your partner gets their way most of the time," "Your partner has more control than you do over whether or not you use condoms," and "Your partner has more control than you do over whether or not you have sex." The 4-point scale (Cronbach $\alpha$ of 0.69 ) was dichotomized for analytic purposes, with score of 0 to 2 indicating high relationship control and 3 to 4 indicating low control. Additional details for the scale can be found elsewhere. ${ }^{16}$

\section{Measure of Life Goals}

The variable of life goals was constructed from 4 statements concerning the future goals and opportunities of the respondent. The statements were: "I have long-range goals for myself," "I think I will have many opportunities in life," "I know what I want out of life," and "I have a good idea of where I am headed in the future." Responses to all statements were "agree/ disagree," and each respondent was given a point on the scale for each "agree" response for a score ranging from 0 to 4 . The Cronbach $\alpha$ for this scale of life goals was 0.70 for women and men.

\section{Statistical Analysis}

The sample for this analysis was restricted to sexually experienced youth, defined as any youth who has ever engaged in anal or vaginal sex $(n=7409)$. The sample was weighted to account for differential sampling probabilities and to represent the distribution of young people aged 15 to 24 years living in South Africa based on the 2001 National Census data. All analyses were conducted using STATA 8.0 (College Station, TX) and used the svy commands to adjust for the sampling strata, PSUs, and population weights. We first report participant characteristics by self-efficacy status for the sample (Table 2). Next, we stratified our sample by gender and show the proportion of respondents reporting consistent condom use according to their answers for each question of the self-efficacy scale (see Table 1). We then performed bivariate logistic regression to determine the association between the variables identified by our conceptual model and the outcome of high self-efficacy (Tables $3,4)$. Bivariate logistic regression was also performed to determine the association between 
the independent variable of high self-efficacy and the dependent variable of condom use consistency by gender, which is the behavior of interest in our conceptual model (see Fig. 1).

Finally, we used a multiple logistic regression model to examine the association between the outcome of high self-efficacy and the candidate factors from our conceptual model in female and male respondents, controlling for sociodemographic variables (see Tables 3 , 4). Odds ratios (ORs) and 95\% confidence intervals were computed for each variable in the bivariate and multivariate models. Because the data are cross-sectional, our modeling is not able to establish causality or the direction of association between self-efficacy and candidate variables from our conceptual model.

\section{RESULTS}

Characteristics by self-efficacy status of the sample of 7409 sexually active South African youth are reported in Table 2. HIV prevalence in the sample reached $19.3 \%$ for female respondents and $6.1 \%$ for male respondents, and HIV status did not vary significantly according to self-efficacy status. Approximately $42 \%$ of female respondents with low selfefficacy reported using a condom during their last sexual encounter, whereas $65.5 \%$ of female respondents with high self-efficacy reported using a condom at their last sexual encounter. For male respondents, $54.3 \%$ versus $75.0 \%$ reported using a condom at their last sexual encounter for low and high self-efficacy, respectively. The prevalence of the respondent characteristics is shown in Table 2. In bivariate analysis, female and male respondents with high self-efficacy were more likely to use condoms with their most recent partner than those with low self-efficacy (female respondents: OR $=2.37,95 \%$ CI: 1.43 to 3.91; male respondents: $\mathrm{OR}=3.11,95 \%$ CI: 2.39 to 4.04 ).

Table 1 shows the responses to the 5 questions comprising the self-efficacy index and the proportion of respondents reporting consistent condom use, stratified by gender. For each of the 5 self-efficacy questions, female and male respondents with high self-efficacy reported higher proportions of consistent condom use than those with low self-efficacy.

We then examined the factors associated with self-efficacy for young women and men. Young women who reported having knowledge of how to avoid HIV infection, who have spoken with someone other than a parent or guardian about HIV/AIDS, and who have life goals were more likely to have high self-efficacy in the adjusted model (see Table 3). Factors significantly associated with low self-efficacy for young women in the adjusted model included not using condoms the first time they had sex, a history of having sex when they did not want to, and believing that condom use is a sign of not trusting one's partner.

Among young men, factors that were significantly associated with high self-efficacy in the adjusted model included taking HIV seriously, believing that they are at no risk of HIV infection, reporting that it is easy to get condoms if they want or need them, and having life goals. Young men with low self-efficacy were more likely not to use condoms the first time they had sex, to have a history of having sex when they did not want to, and reporting that they would not be friends with a person with HIV/AIDS in the adjusted model.

\section{DISCUSSION}

Using the SCM as a framework to explore self-efficacy, we were able to identify factors associated with self-efficacy for young women and men. The model was successful in identifying factors in each of the 6 domains of the SCM, many of which are potentially mutable factors that may be amenable to interventions aimed at increasing self-efficacy and condom use in South African youth. In the domain of knowledge, young women who 
reported knowledge of how to avoid HIV and young men who said they take HIV seriously had higher self-efficacy scores. Interestingly, this study found that most men and women in the sample stated that they take HIV infection seriously and that they have knowledge of how to avoid HIV. Yet, less than half of the young men and less than one third of the young women in this nationally representative study reported consistent condom use. These results suggest that although knowledge of the risks of HIV/AIDS may be an important component of campaigns to promote condom use, we must also focus efforts on understanding and exploring the complex construction of sexuality among adolescents and move beyond the traditional assumption that sexual behavior is the result of rational decisions based on knowledge. $19^{-21}$ For example, participatory HIV prevention programs that are peer based and understand sexuality in youth to be a socially negotiated phenomenon as opposed to an individual decision may be more appropriate for this adolescent population. Such programs seek to provide an intellectual understanding of how certain social conditions (eg, gender identity, poverty) may contribute to the risk of HIV and to provide a context for the collective renegotiation of dominant norms of behavior that may be placing young people's sexual health at risk. ${ }^{22-} 24$

The domain of outcome expectations in the SCM revealed that beliefs about condoms were an important factor influencing self-efficacy. Consistent with other studies in South Africa and in developed countries, such as the United Kingdom and Australia, we found that for young women and men, low self-efficacy is associated with the belief that using condoms is a sign of not trusting one's partner. $19,25^{-27}$ These results suggest that young men and women who believe that condom use implies distrust of their partner are less likely to believe that they can successfully negotiate condom use in sexual encounters. The issue of trust in relation to condom use in South Africa is complex and has been extensively debated. Studies of adolescent sexuality show that trust is viewed as desirable in adolescent relationships, yet it is claimed for relationships in which traditional notions of trust (eg, monogamy) are known to be absent. ${ }^{25,27,28}$ Thus, a young woman with knowledge of her partner having multiple other sexual partners may still report that she trusts him and that requesting the use of condoms would be seen to violate this trust. We hypothesize from our data that young women who are able to challenge such beliefs about condoms have higher self-efficacy for condom use and sexual negotiation, which, in turn, may lead to more consistent condom use. These women may provide valuable insight as to alternative ways to think about condom use as an acceptable part of negotiating sexual encounters among South African youth. Ultimately, a better understanding of these issues may inform the development of interventions that challenge the perception of condoms and the social context within which condom use is negotiated in South Africa.

In the domain of goals of the SCM, having life goals was associated with high self-efficacy for young men and women. To our knowledge, no nationally representative studies of sexual risk behavior and condom use in adolescents have examined the relation between life goals and self-efficacy, despite frequent use of the SCM for exploring such behaviors. In the United States, small studies of Latino youth have shown that having educational goals is a significant negative predictor of intentions to have sex and sexual experiences in the prior 3 months. ${ }^{29,30}$ Similar studies of sexual experiences and life goals in African-American youth have not demonstrated the same associations, however. ${ }^{31}$ Further investigation of the relation between life goals, self-efficacy, and risky sexual behavior is warranted, because we are limited in drawing conclusions about causality between these factors with our crosssectional data. These results lead us to hypothesize that programs aimed at helping adolescents to create future goals may also foster the development of strong self-esteem and self-efficacy for the individual, which may, in turn, result in less risky sexual behavior and improved condom use consistency. 
In the domain of sociostructural factors, communication about HIV/AIDS was associated with self-efficacy in young women. Female respondents who spoke with someone other than a parent or guardian about HIV/AIDS were more likely to have high self-efficacy, although this was not true among male respondents. This is consistent with research from Europe and America, which has suggested that youth are more likely to practice safe sex if they have opportunities to communicate openly about sex with sexual partners, peers, and parents or other significant adults. ${ }^{26,32,33}$ A study of college students in the United States showed that discussion of safe sex with friends was a strong predictor of practicing safer sex. ${ }^{34}$ In this same study, gender differences were also found, because women were more likely than men to pressure their friends to use condoms. ${ }^{34}$ Studies from South Africa have demonstrated that women who are unable to communicate with their partners are more likely to be involved in risky sexual behavior. ${ }^{16,22,27}$ This relation between communication with a partner and condom use has not been found in South African men. We hypothesize that this may be the case because gender norms within predominant South African culture establish men as the decision makers about many aspects of the sexual encounter, including the use of condoms. ${ }^{27,35,36}$ In this role, men have the "right" to make decisions about using condoms without any discussion, whereas women who want to use condoms must enter into a process of negotiation with partners that runs contrary to accepted constructions of female sexual norms. In such situations, women who communicate about the risks associated with not using condoms, such as HIV/AIDS and pregnancy, may be more likely to use condoms. In this context, self-efficacy for condom use and sexual negotiation would be expected to be associated with communication about HIV/AIDS for women, as has been found in our study. These results indicate that particularly for female youth, emphasis on communication with friends and partners regarding the risks of HIV/AIDS and the use of condoms may be an important component of intervention programs aimed at improving self-efficacy and condom use among young women in South Africa.

There were some limitations in our study. First, because of the cross-sectional nature of our data, we are not able to draw conclusions about causal relations between the variables in our conceptual model and self-efficacy. Second, sensitive sexual behaviors might have been underreported because of social desirability bias. Third, the study results may not be generalizable to other countries, although we believe that global lessons can be learnt from these results.

In this study, we found the SCM to be useful in identifying factors associated with selfefficacy for condom use in South African youth. The model captured significant factors associated with self-efficacy in each of the 6 domains of the SCM and highlighted differences in the sociostructural factors that influence young women and men. The findings in this study have important implications, because they inform researchers, communities, and policy makers that a broad range of factors related to self-efficacy may influence condom use and that knowledge of and access to condoms is only a small component of ensuring consistent use. In addition, the results of this study emphasize the importance of considering the unique social and cultural context of adolescent sexuality and gender roles in South African youth, with the goal of tailoring interventions to young men and women separately when addressing condom use and improved self-efficacy.

\section{Acknowledgments}

The authors acknowledge the adolescent research team at the RHRU, University of the Witwatersrand, Johannesburg, South Africa, for the study design, development, and implementation. They also thank Development Research Africa, Durban, South Africa, for data collection and entry and Contract Laboratory Services of the University of the Witwatersrand, Johannesburg, South Africa, for all laboratory work. 
Funding for the National Youth Survey was provided by the Kaiser Family Foundation. J. N. Sayles is a National Research Service Award Fellow in the Division of General Internal Medicine and Health Services Research, UCLA, and was partially supported by the UCLA Primary Care Research Fellowship Program.

\section{REFERENCES}

1. Pettifor AE, Rees HV, Kleinschmidt I, et al. Young people's sexual health in South Africa: HIV prevalence and sexual behaviors from a nationally representative household survey. AIDS 2005;19:1525-1534. [PubMed: 16135907]

2. South African National HIV Prevalence, Behavioural Risks and Mass Media: Household Survey 2002: Executive Summary. Human Sciences Research Council; Cape Town, South Africa: 2002. Nelson Mandela/HSRC Study of HIV/AIDS.

3. South African National HIV Prevalence, Behavioural Risks and Mass Media: Household Survey 2005: Executive Summary. Human Sciences Research Council; Cape Town, South Africa: 2005. Nelson Mandela/HSRC Study of HIV/AIDS.

4. Hendriksen ES, Lee SJ, Coates TJ, et al. Ther RHRU National Youth Survey. Predictors of condom use among South African youth age 15-24. Am J Public Health. in press.

5. Warren M. Condom use in South Africa: facts and fantasies. Natl AIDS Bull 1997;1:4-6.

6. Shelton JD, Johnston B. Condom gap in Africa: evidence from donor agencies and key informants. BMJ 2001;323:139. [PubMed: 11463681]

7. James S, Reddy SP, Taylor M, et al. Young people, HIV/AIDS/STIs and sexuality in South Africa: the gap between awareness and behaviour. Acta Paediatr 2004;93:264-269. [PubMed: 15046286]

8. Baele J, Dusseldorp E, Maes S. Condom use self-efficacy: effect on intended and actual condom use in adolescents. J Adolesc Health 2001;28:421-431. [PubMed: 11336873]

9. Mashegoane S, Moalusi KP, Peltzer K, et al. The prediction of condom use intention among South African university students. Psychol Rep 2004;95:407-417. [PubMed: 15587200]

10. Giles M, Liddell C, Bydawell M. Condom use in African adolescents: the role of individual and group factors. AIDS Care 2005;17:729-739. [PubMed: 16036259]

11. Fischer JD, Fisher AW. Changing AIDS risk behaviour. Psychol Bull 1992;111:455-474. [PubMed: 1594721]

12. Catania JA, Kegeles SM, Coates TJ. Towards an understanding of risk behaviour: an AIDS risk reduction model (ARRM). Health Educ Q 1990;17:53-72. [PubMed: 2318652]

13. Bandura A. Health promotion by social cognitive means. Health Educ Behav 2004;31:143-164. [PubMed: 15090118]

14. Bandura A. Self-efficacy: toward a unifying theory of behavioral change. Psychol Rev 1977;84:191-215. [PubMed: 847061]

15. Hanna K. An adolescent and young adult condom self-efficacy scale. J Pediatr Nurs 1999;14:5966. [PubMed: 10063250]

16. Pettifor AE. Sexual power and HIV risk, South Africa. Emerg Infect Dis 2004;10:1996-2004. [PubMed: 15550214]

17. Pulerwitz J, Gortmaker SL, De Jong W. Measuring sexual relationship power in HIV/STD research. Sex Roles 2000;42:637-650.

18. Pulerwitz J, Amaro H, De Jong W, et al. Relationship power, condom use and HIV risk among women in the USA. AIDS Care 2002;14:789-800. [PubMed: 12511212]

19. Ingham, R.; Woodcock, A.; Stenner, K. The Limitations of Rational Decision-Making Models as Applied to Young People's Sexual Behaviour. Falmer Press; London, UK: 2001.

20. Joffe H. AIDS research and prevention: a social representational approach. Br J Med Psychol 1996;69:169-190. [PubMed: 8883972]

21. MacPhail C. Adolescents and HIV in developing countries: new research directions. Psychology in Society 1998;24:69-87.

22. Campbell C, MacPhail C. Peer education, gender and the development of critical consciousness: participatory HIV prevention by South African youth. Soc Sci Med 2002;55:331-345. [PubMed: 12144146] 
23. Campbell C, Jovchelovitch S. Health, community and development: towards a social psychology of participation. Journal of Applied and Community Social Psychology 2000;10:255-270.

24. Campbell C, Williams B. Evaluating HIV prevention programmes: conceptual challenges. Psychology in Society 1998;24:57-68.

25. MacPhail C, Campbell C. 'I think condoms are good but, aai, I hate those things': condom use among adolescents and young people in a Southern African township. Soc Sci Med 2001;52:16131627. [PubMed: 11327136]

26. Holland, J.; Ramazanoglu, C.; Scott, S., et al. Between embarrassment and trust: young women and the diversity of condom use. In: Aggelton, PDP.; Hart, G., editors. AIDS: Responses, Interventions and Care. Falmer Press; London, UK: 1991. p. 127-148.

27. Hoffman SOL, Harrison A, Dolezal C, et al. HIV risk behaviours and the context of sexual coercion in young adults' sexual interactions: results from a diary study in rural South Africa. Sex Transm Dis 2006;33:52-58. [PubMed: 16385222]

28. Meyer-Weitz A, Reddy P, Weijts W, et al. The socio-cultural contexts of sexually transmitted diseases in South Africa: implications for health education programmes. AIDS Care 1998;10(Suppl 1):S39-S55. [PubMed: 9625893]

29. Leibowitz S, Castellano DC, Cuellar I. Factors that predict sexual behaviors among young Mexican American adolescents: an exploratory study. Hisp J Behav Sci 1999;24:470-479.

30. Villarruel AM, Jemmott JB III, Jemmott LS, et al. Predictors of sexual intercourse and condom use intentions among Spanish-dominant Latino youth: a test of the planned behavior theory. Nurs Res 2004;53:172-181. [PubMed: 15167505]

31. Salazar LF, DiClemente RJ, Wingood GM, et al. Self-concept and adolescents' refusal of unprotected sex: a test of mediating mechanisms among African American girls. Prev Sci 2004;5:137-149. [PubMed: 15470935]

32. Aggleton P, Campbell C. Working with young people- towards an agenda of sexual health. Sex Relationship Ther 2000;15:283-296.

33. Hiller L, Harrison L, Warr D. When you carry condoms all the boys think that you want it: negotiating competing discourses about safe sex. J Adolesc 1998;21:15-19. [PubMed: 9503072]

34. Lear D. Sexual communication in the age of AIDS: the construction of risk and trust among young adults. Soc Sci Med 1995;41:1311-1323. [PubMed: 8545683]

35. Dunkle KL, Jewkes RK, Brown HC, et al. Gender-based violence, relationship power, and risk of HIV infection in women attending antenatal clinics in South Africa. Lancet 2004;363:1415-1421. [PubMed: 15121402]

36. Varga C. How gender roles influence sexual and reproductive health among South African adolescents. Stud Fam Plann 2003;34:160-172. [PubMed: 14558319] 


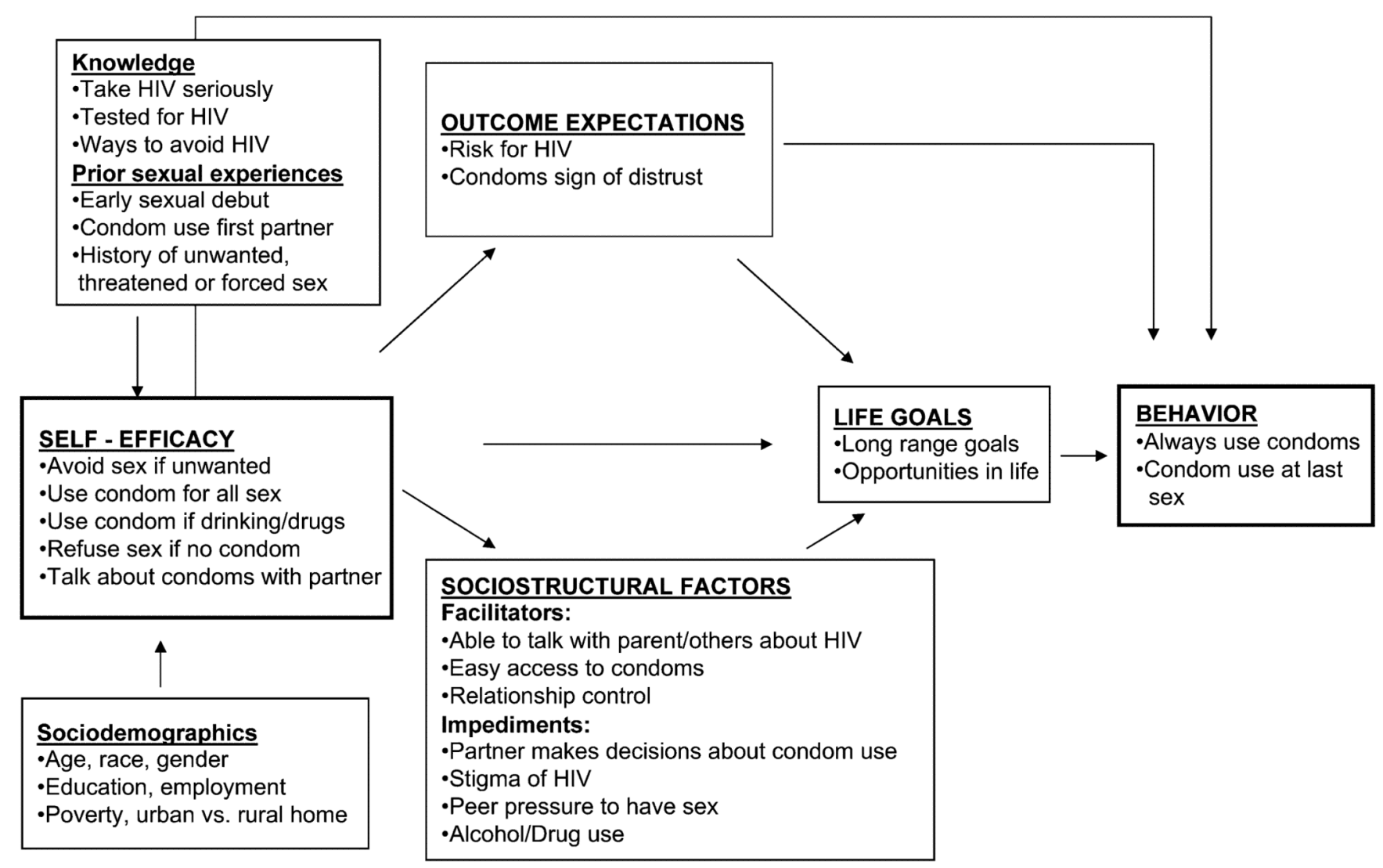

FIGURE 1.

Paths of influence in the SCM. Beliefs of personal efficacy for condom use and sexual negotiation affect the behavior of condom use directly by their impact on goals, outcome expectations, and perceived facilitators and impediments. Knowledge about HIV infection as well as sociodemographic characteristics and prior sexual experiences also may influence self-efficacy for condom use (Adapted from Bandura A. Health promotion by social cognitive means. Health Educ Behav. 2004;31:145; with permission.) 


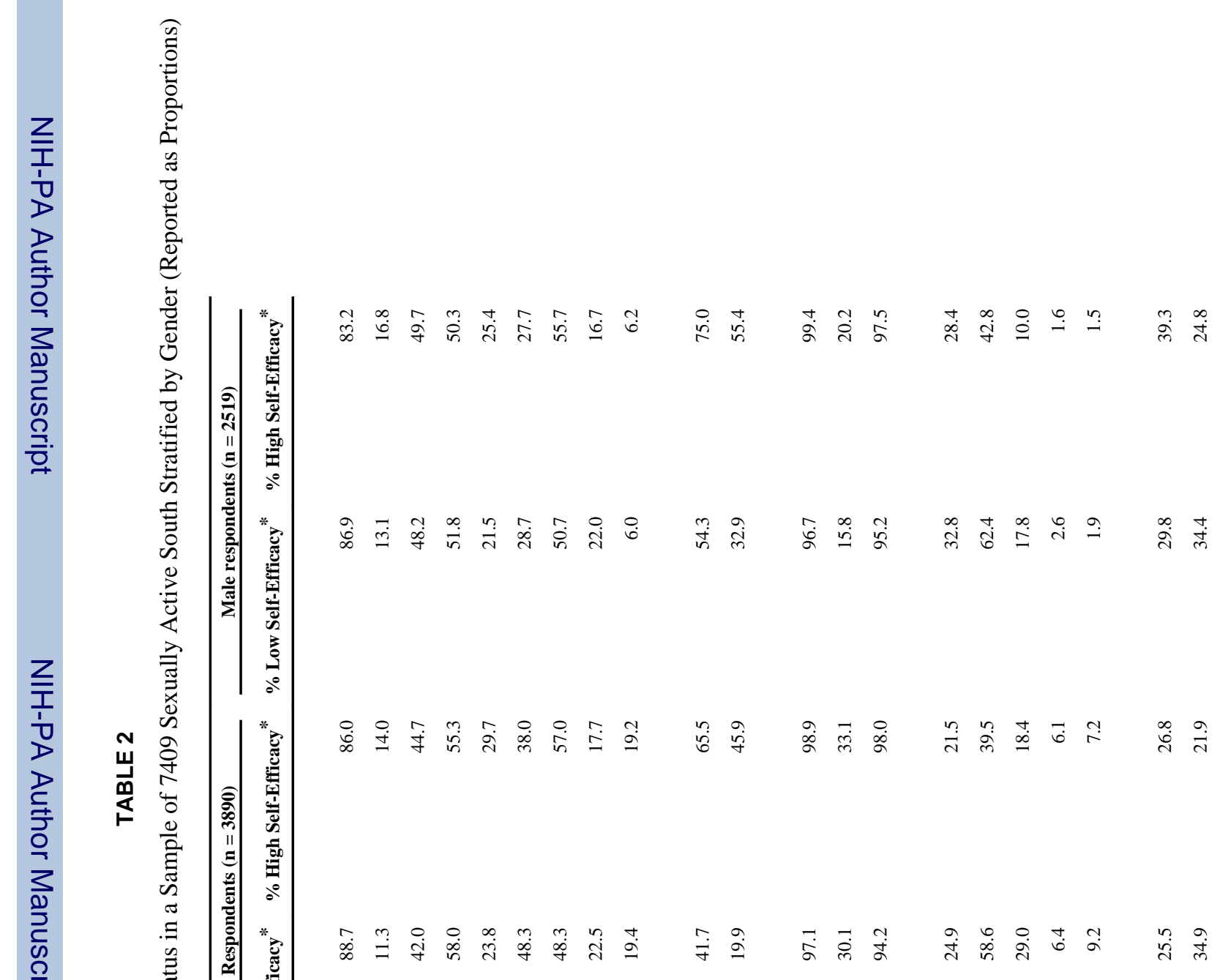




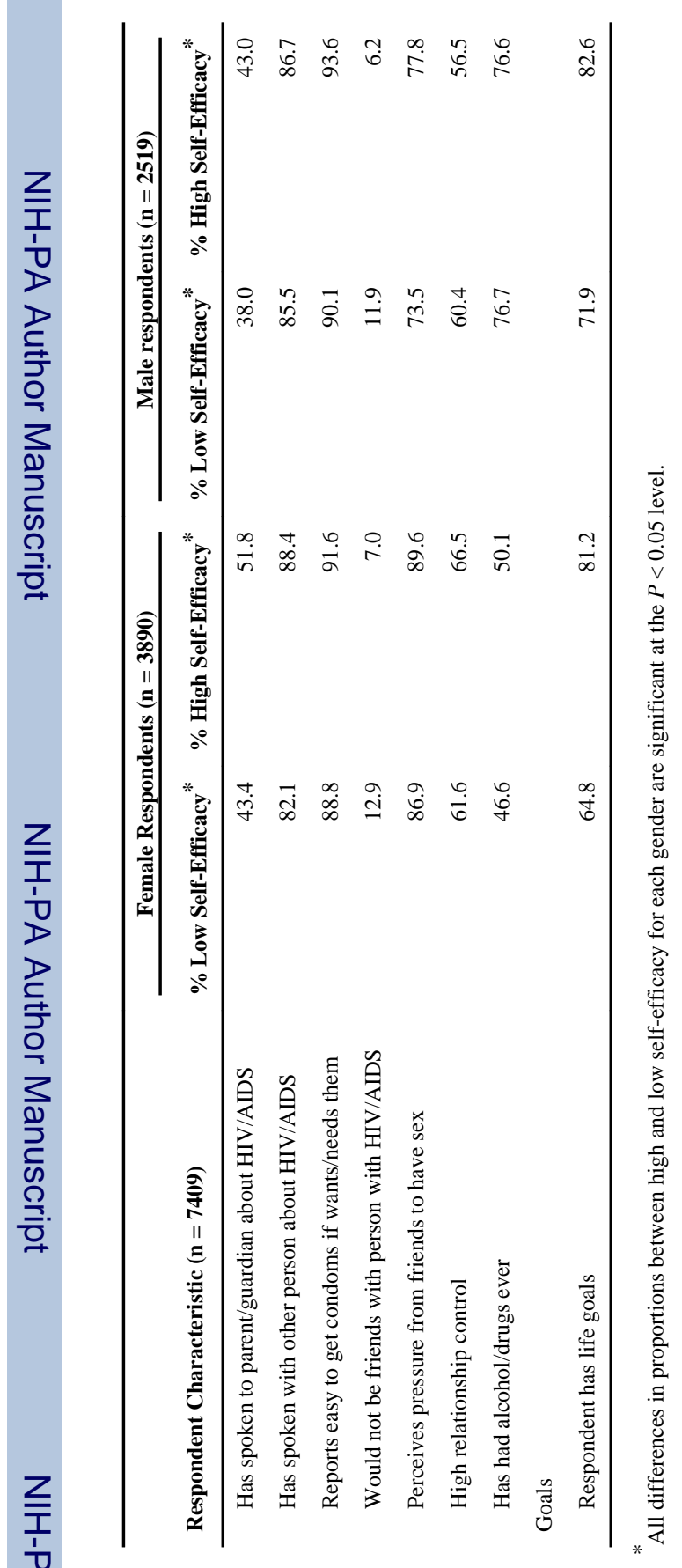




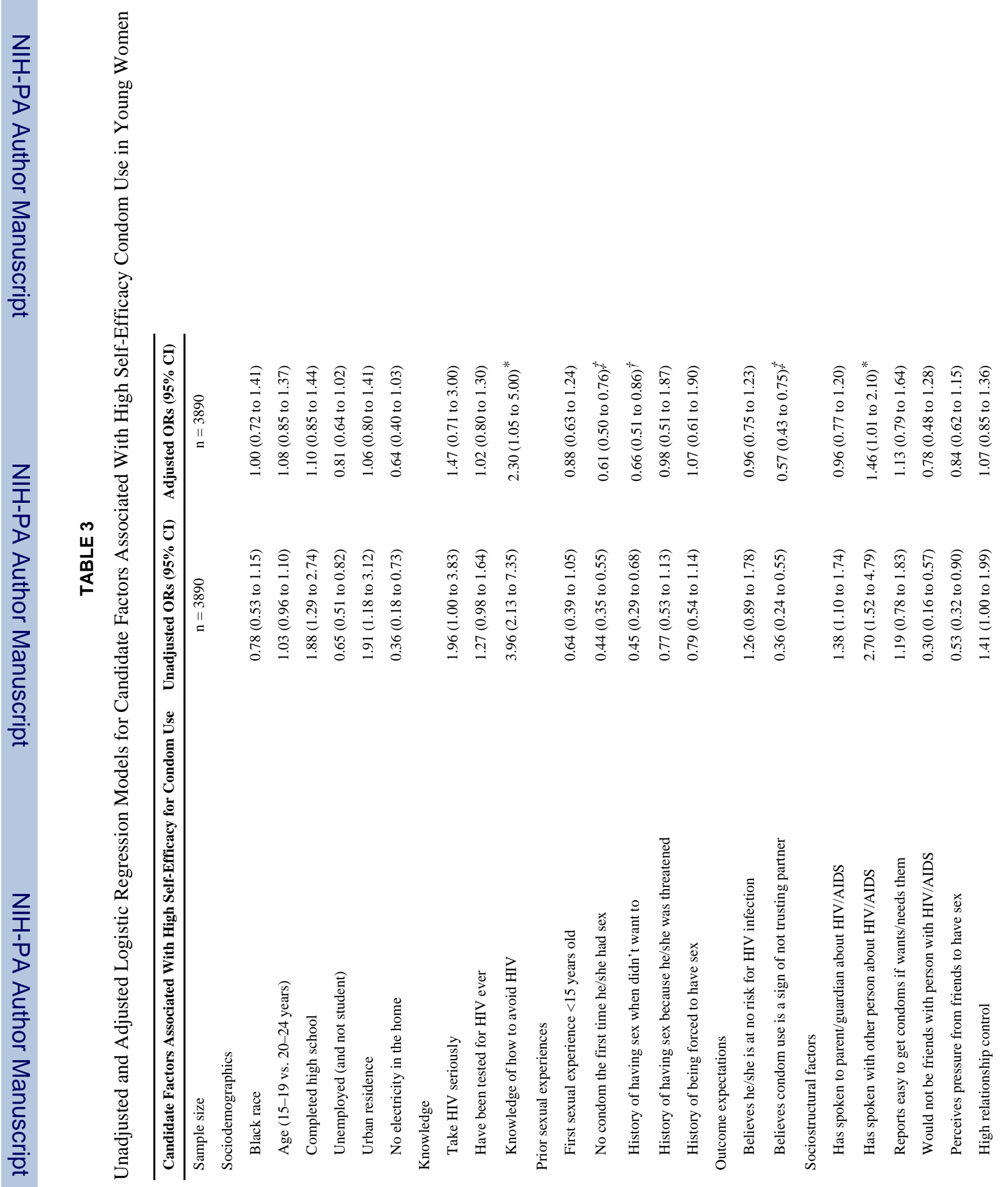




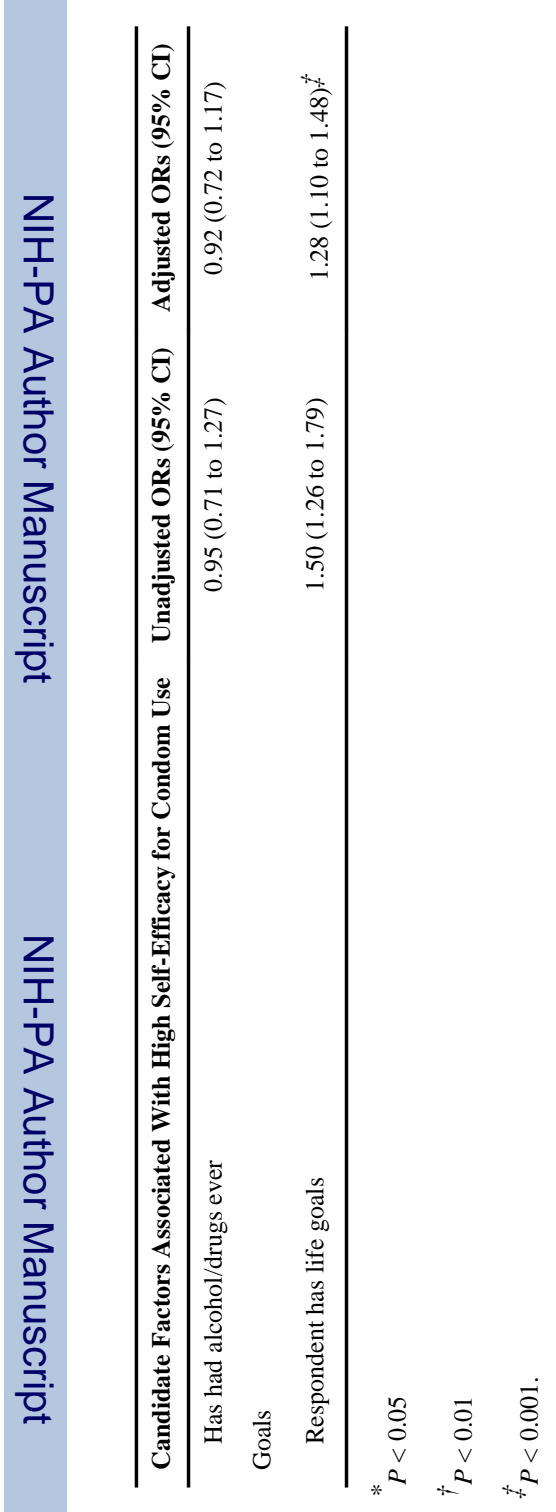




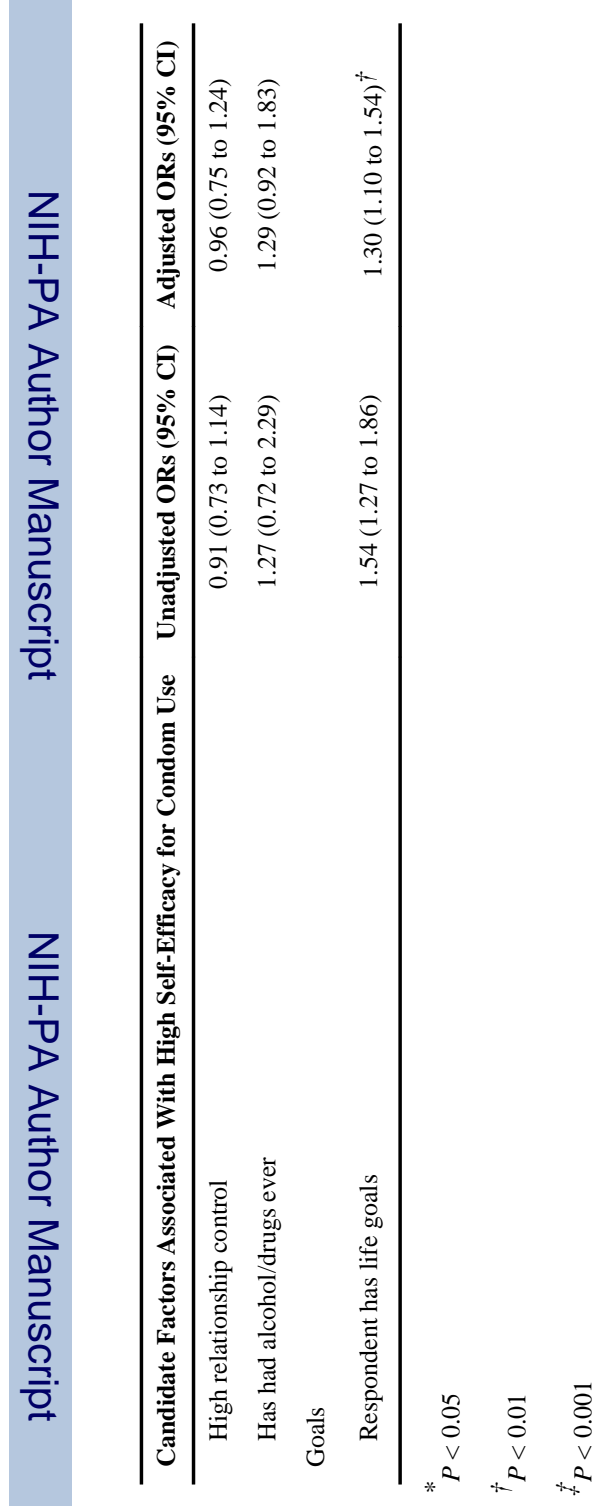

